\title{
Correction to: Canine Endotheliochorial Placenta: Morpho-Functional Aspects
}

\author{
Mariusz P. Kowalewski, Ali Kazemian, Karl Klisch, Tina Gysin, \\ Miguel Tavares Pereira, and Aykut Gram
}

\section{Correction to:}

\section{Chapter 8 in: R. D. Geisert, T. Spencer (eds.), Placentation in Mammals, Advances in Anatomy, Embryology and Cell Biology 234, https://doi.org/10.1007/978-3-030-77360-1_8}

Chapter 8 was inadvertently published with errors and the following corrections were updated:

On page 159, the word "see" in italics was changed to roman type in the line "(for details see in...".

On page 160, the phrase "The immunosuppressive Treg cells appear" was changed to "The immunosuppressive regulatory $\mathrm{T}$ and natural killer (NK) cells appear".

On page 160, hyperlink was added for the citation (Tavares Pereira et al. 2021).

On page 161, the phrase "The lumen of the uterine glands develops..." was changed to "The lumina of the uterine glands develop...".

On page 161, the phrase "expands into the extraembryonic coelom..." was changed to "expands into the chorionic cavity...".

On page 162, Figure 1 was replaced with a high-resolution figure.

On page 163, the part labels $(\mathbf{a}, \mathbf{b})$ in Figure 2 did not match with the figure and caption, and were updated uniformly.

On page 165, Figure 3 was replaced with a high-resolution figure.

On page 165, the caption of Figure 3, the text was "Histological appearance of the canine placenta" changed to "Histological appearance of the canine fully developed placenta".

\footnotetext{
The updated online version of this chapter can be found at https://doi.org/10.1007/978-3-030-77360-1_8
} 
On page 166, Figure 4 was replaced with the corrected figure.

On page 170, the following sentence was added: "Furthermore, the uterine immune milieu appears to be associated with an increased presence of immune cells during parturition, involving macrophages involved in tissue remodeling, as well as Th and Treg (own unpublished data).

On page 179, doi links were removed from the below two references.

"Nowak M, Rehrauer H, Ay SS, Findik M, Boos A, Kautz E et al (2019) Gene expression profiling of the canine placenta during normal and antigestagen-induced luteolysis. Gen Comp Endocrinol 282:113194.

and

“Tavares Pereira M, Nowaczyk R, Payan-Carreira R, Miranda S, Aslan S, Kaya D, Kowalewski MP (2021) Selected uterine immune events associated with the establishment of pregnancy in the dog. Front Vet Sci 7:625921”. 